\title{
EFFICACY OF 5\% POTASSIUM HYDROXIDE VERSUS 10\% POTASSIUM HYDROXIDE SOLUTION FOR THE TREATMENT OF MOLLUSCUM CONTAGIOSUM AT A TERTIARY CARE HOSPITAL
}

\author{
Hina Saleem Baloch, Najia Ahmed, Arfan ul Bari, Omer Farooq, Abdullah Waqar Ahmad Qureshi* \\ Pakistan Naval Ship Hospital, Shifa Karachi Pakistan, *Aster Clinic, Dubai
}

\begin{abstract}
Objective: To compare the efficacy of $5 \%$ potassium hydroxide $(\mathrm{KOH})$ and $10 \%$ potassium hydroxide $(\mathrm{KOH})$ solution for the treatment of molluscum contagiosum at a tertiary care Hospital.

Study Design: Quasi-experimental study.

Place and Duration of Study: Dermatology Department, Tertiary Care Hospital Karachi, from Oct 2020 to Apr 2021.

Methodology: Sixty patients with molluscum contagiosum who fulfilled the inclusion and exclusion criteria were enrolled in the outpatient department of tertiary care hospital in Karachi. Patients were divided into two groups, A (5\% KOH) and B (10\% $\mathrm{KOH})$ of 30 patients each. Potassium Hydroxide $(\mathrm{KOH})$ solution was applied at home using the cotton-tipped applicator twice daily. Follow-up of patients was done at 2-weekly intervals for 12 weeks. Efficacy was measured based on the resolution of lesions or improvement from baseline.

Results: Complete response occurred in $23(76.7 \%)$ cases in 10\% $\mathrm{KOH}$ Group while $6(20 \%)$ in 5\% KOH Group, Partial response occurred in $6(20 \%)$ in $10 \% \mathrm{KOH}$ group while $15(50 \%)$ in $5 \% \mathrm{KOH}$ group, No response occurred in $1(3.33 \%)$ in $10 \%$ $\mathrm{KOH}$ group and $9(30 \%)$ in $5 \% \mathrm{KOH}$ group $(p<0.001)$.

Conclusion: $10 \%$ Potassium Hydroxide $(\mathrm{KOH})$ is an efficient modality for the treatment of molluscum contagiosum compared to $5 \%$ Potassium Hydroxide $(\mathrm{KOH})$.
\end{abstract}

Keywords: Efficacy, Molluscum contagiosum, Potassium hydroxide (KOH), Safety.

How to Cite This Article: Baloch HS, Ahmed N, Bari AU, Farooq O, Qureshi AWA. Efficacy of 5\% Potassium Hydroxide Versus 10\% Potassium Hydroxide Solution for the Treatment of Molluscum Contagiosum at a Tertiary Care Hospital. Pak Armed Forces Med J 2021; 71(6): 2135-2138. Doi: https://doi.org/10.51253/pafmj.v71i6.6807

This is an Open Access article distributed under the terms of the Creative Commons Attribution License (https://creativecommons.org/licenses/by-nc/4.0/), which permits unrestricted use, distribution, and reproduction in any medium provided the original work is properly cited.

\section{INTRODUCTION}

Molluscum contagiosum (MC) is a common viral infection caused by the molluscum contagiosum virus (MCV) which predominantly involves the skin and mucous membrane. MCV belongs to the Poxviridae family that is a double-stranded DNA virus. ${ }^{1}$ It predominantly affects children, sexually active adults, and immunocompromised individuals. The worldwide incidence of MC infection is estimated to be between 2$8 \%$. In Pakistan, MC constitutes $10.6 \%$ of all viral skin diseases. ${ }^{2}$

Typically, Molluscum contagiosum lesions are rounded, dome-shaped, and white to flesh-coloured, pearly papule. Transmission of MC is by direct contact with infected skin (contact can be sexual, non-sexual or autoinoculation) or by contaminated fomites like towels or sponges, etc. ${ }^{3,4}$ Presentation of the lesions of MC can be single, multiple, or clustered, with sometimes appearance of an erythematous halo. ${ }^{5}$

The diagnosis of Molluscum contagiosum is clinical, primarily based on the distinguishing traits of the

Correspondence: Dr Hina Saleem Baloch, Dept of Dermatology, Pakistan Naval Ship Shifa Hospital, Karachi Pakistan

Received: 02 Jun 2021; revision received: 18 Oct 2021; accepted: 28 Oct 2021 lesions. ${ }^{6}$ Histologic examination of a biopsied lesion can be used to confirm the diagnosis, which shows molluscum bodies (Henderson-Paterson bodies) in the keratinocyte cytoplasm. A clinical tool that can aid in diagnosis is dermoscopy which shows the central area of amorphous material (can be white to yellow), with peripherally arranged vessels (linear or branched). Although lesions of MC may resolve spontaneously after several months, they can be symptomatic and cause psychosocial distress. Therefore, patients may seek treatment for social/aesthetic reasons, and additionally due to worries of spreading disease to others. There are many treatments for $\mathrm{MC}$, including physical elimination and systemic and topical interventions like curettage, cryotherapy, pricking with a sterile needle, photodynamic therapy, Salicylic Acid, Glycolic Acid, Tretinoin, Podophyllin, Antharidin, Trichloroacetic Acid, 5Fluorouracil, Silver Nitrate, intralesional PPD and Potassium Hydroxide (KOH). ${ }^{7-10}$

Most treatments for Molluscum contagiosum are hospital-based and require multiple visits, having negative aesthetic, psychological and socioeconomic effects. $\mathrm{KOH}$ can be a favourable treatment of $\mathrm{MC}$ due to fewer hazards and the convenience of self- 
application. Currently, in Pakistan, lower concentrations of $\mathrm{KOH}$ are being used in many setups because of fear of burning at the site of application which leads to undertreatment and incomplete recovery. There is a paucity of data on this subject in our local population. Moreover, in Pakistan previous studies are either not comparative or are not blinded. Hence, we compared the response of Mollusca to $5 \%$ vs $10 \%$ of $\mathrm{KOH}$. The results of this study will help to evaluate which concentration of $\mathrm{KOH}$ is more effective for the management of $\mathrm{MC}$ in our local population. The management option with better results may be used as the preferred treatment for MC.

\section{METHODOLOGY}

This quasi-experimental study was conducted at the department of Dermatology, Tertiary care Hospital, Karachi Pakistan, from October 2020 to April 2021. Approval was sought from the hospital research ethics committee (ERC/2020/Derma/00) before conducting the study. We calculated a sample size of 60 patients, using the World Health Organization sample size calculator with a level of significance: $5 \%$, power of test: $95 \%$, anticipated first population proportion: $0 \%$ 11 and anticipated second population proportion: $41.2 \% .{ }^{11}$

Sixty patients who fulfilled the inclusion/exclusion criteria were enrolled through non-probability consecutive sampling technique and randomized into two groups $\mathrm{A}$ and $\mathrm{B}$ of 30 patients each by lottery method. All patients in Group A were provided with 5\% $\mathrm{KOH}$ solution and patients in group $\mathrm{B}$, with $10 \% \mathrm{KOH}$ solution.

Inclusion Criteria: Patients having 2-50 lesions for at least one month belonging to the age group 2-14 years were included.

Excluded Criteria: Patients who have taken any therapy for Molluscum contagiosum lesions in the past month, hypersensitivity to $\mathrm{KOH}$ and known immunosuppression were excluded.

Informed written consent was obtained from the parents of the children and demographic details were noted. Complete clinical history along with detailed physical examination was recorded, which included the diagnosis, site, size, and number of lesions. Patients were reviewed at 2 weekly intervals and efficacy was evaluated. Efficacy was categorized as complete response (complete resolution 100\%), partial response (clearing of $\geq 50 \%$ of the Molluscum contagiosum lesions), no response $(<50 \%$ clearance).
Bottles of $5 \% \mathrm{KOH}$ and $10 \% \mathrm{KOH}$ were indistinguishable, and each patient received a bottle (identical) of the solution assigned. The first application of either concentration of $\mathrm{KOH}$ solution was performed by the researcher herself using the cotton-tipped applicator and parents/patients were instructed to carefully observe the method and were advised to apply the solution similarly at home twice daily. Efficacy in two weekly follow-up visits was observed by the principal researcher for a total of 12 weeks. Neither the patients, their parents, nor the researcher knows about the patient's assigned group.

Data was entered and analyzed by using the statistical package for the Social Sciences version (SPSS) 24. The quantitative variables were presented as Mean $\pm \mathrm{SD}$. The qualitative variables were presented as frequency and percentage. Chi-square test was applied to compare outcome (complete response, partial response, no response) between both the groups before and after stratification into male/female and duration of disease. The $p$-value $\leq 0.05$ was considered significant.

\section{RESULTS}

In this study, 60 patients were included, which were divided into two groups of 30 patients each Group A $(5 \% \mathrm{KOH})$ and group B $(10 \% \mathrm{KOH})$ respectively. All 60 patients completed the study. Descriptive statistics of both groups were well-matched (Table-I).

\begin{tabular}{l|c|c} 
Table-I: Descriptive statistics of both groups. \\
\hline Variables & $\begin{array}{c}\text { Group A } \\
\text { (Mean } \pm \text { SD) }\end{array}$ & $\begin{array}{c}\text { Group B } \\
\text { (Mean } \pm \text { SD) }\end{array}$ \\
\hline Age Group (Years) & $8.77 \pm 2.52$ & $7.47 \pm 3.02$ \\
\hline $\begin{array}{l}\text { Duration of } \\
\text { Disease (months) }\end{array}$ & $2.77 \pm 1.04$ & $3.00 \pm 1.08$ \\
\hline Height $(\mathrm{cm})$ & $135.10 \pm 10.73$ & $128.20 \pm 9.41$ \\
\hline Weight $(\mathrm{kg})$ & $26.70 \pm 4.10$ & $28.20 \pm 8.98$ \\
\hline BMI $\left(\mathrm{Kg} / \mathrm{m}^{2}\right)$ & $15.10 \pm 1.90$ & $17.60 \pm 5.80$ \\
\hline Number of Lesion & $14.67 \pm 7.32$ & $16.53 \pm 10.97$ \\
\hline
\end{tabular}

The frequency of duration of lesions in group A was, $18(60 \%)$ and $12(40 \%)$ for $\leq 2$ months and $>2$ months respectively, and in group B it was, 13 (43.3\%) and $17(56.7 \%)$ for $\leq 2$ months and $>2$ months respectively. Stratification concerning the duration of disease in $\leq 2$ months and $>2$ months showed significant findings with the $p$-value of $<0.001$ and $p$-value 0.004 respectively (Table-II).

Frequency distribution of gender showed that out of 30 patients in group A, 16 (53.3\%) and 14 (46.7\%) were male and female respectively. Whereas out of 30 patients in group B, 19 (63.3\%) and 11 (36.7\%) were male and female respectively. Gender had no effects on 
the success of treatment, but the number of lesions does have an impact on treatment outcome. Our study showed that treatment was efficacious in $5(21.7 \%)$ and $13(76.5 \%)$ patients, from groups A and B respectively, who had $<25$ lesions. Efficacy is depicted in TableIII which shows that group B $(10 \% \mathrm{KOH})$ has higher efficacy than group A $(5 \% \mathrm{KOH})$ with a $p$-value $<0.001$ which is significant.

\begin{tabular}{l|c|c|c|c|c} 
Table-II: Effects on the outcome by duration of disease. \\
\hline $\begin{array}{l}\text { Duration } \\
\text { of Disease }\end{array}$ & Group & Complete & Partial & No & \multirow{2}{*}{$\begin{array}{c}p \text { - } \\
\text { value }\end{array}$} \\
\hline \multirow{2}{*}{$\leq 2$ month } & A & - & $9(60)$ & $9(100)$ & \multirow{2}{*}{$<0.001$} \\
\cline { 2 - 5 } & B & $7(100)$ & $6(40)$ & - & \\
\hline \multirow{2}{*}{$>2$ monts } & A & $6(27.3)$ & $6(100)$ & - & \multirow{2}{*}{0.004} \\
\cline { 2 - 5 } & B & $16(72.7)$ & - & $1(100)$ & \\
\hline
\end{tabular}

Table-III: Efficacy in the study groups.

\begin{tabular}{|c|c|c|c|}
\hline \multirow[t]{2}{*}{ Efficacy } & $\begin{array}{c}5 \% \text { KOH } \\
\text { Group, } n(\%)\end{array}$ & $\begin{array}{c}10 \% \mathrm{KOH} \\
\text { Group, n (\%) }\end{array}$ & \multirow{2}{*}{$\begin{array}{c}p \text { - } \\
\text { value }\end{array}$} \\
\hline & No & No & \\
\hline Complete response & $6(20)$ & $23(76.7)$ & \multirow{3}{*}{$<0.001$} \\
\hline Partial response & $15(50)$ & $6(20)$ & \\
\hline No response & $9(30)$ & $1(3.3)$ & \\
\hline
\end{tabular}

In Group A $6(20 \%)$ patients showed complete response out of the 30 , with zero response of patients by 4 weeks, 2 patients showed complete response by 8 weeks and 4 by 12 weeks. In Group B complete response was seen in $23(76.7 \%)$ out of a total of 30 patients, of which 17 patients showed complete response by 4 weeks, another 5 by the end of 8 weeks and 1 more by the end of 12 weeks. Figure (A \& B) showed the response of $10 \% \mathrm{KOH}$ after 8 weeks of treatment. There was no severe local or systemic adverse reaction reported in our study. The only finding was slight erythema and tingling sensation immediate post-application of $10 \% \mathrm{KOH}$ sol while no erythema following application of $5 \% \mathrm{KOH}$ sol was observed.

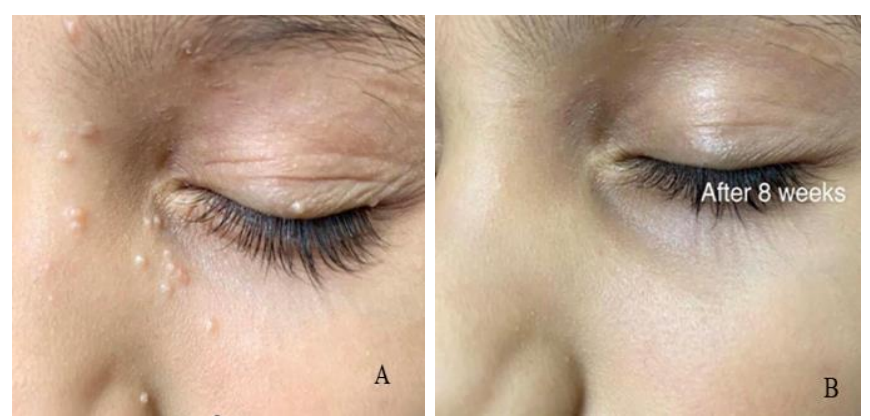

Figure: Response of $10 \% \mathrm{KOH}(\mathrm{A})$ before treatment (B) after 8 weeks of treatment.

\section{DISCUSSION}

The requirement for active treatment for Molluscum contagiosum is controversial; however, there is a consensus that it need to be indicated in instances of widespread disease, associated with complications or aesthetical complaints, parents also seek treatment for their children in worry of the unfolding of lesions to other youngsters. A variety of therapeutic options are available to treat MC but they are mostly hospitalbased, induce pain and require repeated sittings based upon their response which leads to a decrease in patient compliance. Thus, leading to the quest to search for an alternative treatment modality that is easily usable at home and pain-free leading to a higher compliance rate.

We compared the efficacy of $5 \% \mathrm{KOH}$ and $10 \%$ $\mathrm{KOH}$ solution in the treatment of $\mathrm{MC}$ in children and found excellent results of the $10 \% \mathrm{KOH}$ group as compared to the $5 \% \mathrm{KOH}$ group with average lesion clearance in 4 weeks. The results of our study are comparable with the study of Rahman et al, ${ }^{12}$ who determined the efficacy of $10 \% \mathrm{KOH}$ solution for treating $\mathrm{MC}$. Complete, partial and no response occurred in 23 $(76.7 \%), 6(20 \%)$ and $1(3.33 \%)$ cases in the $10 \% \mathrm{KOH}$ group respectively in our study, while complete, partial and no response occurred in $20(71.4 \%), 2(7.1 \%)$ and $2(7.1 \%)$ cases in their study respectively. They have evaluated the fourth category of near-complete response as well, which showed 4 (14.3\%) improvement. The success rate of $10 \% \mathrm{KOH}$, reported by different studies ranges between $41.2-92.5 \% .{ }^{13-16} \mathrm{KOH}$ destroys keratinocytes leading to stimulation of innate and cell-mediated immune response that inhibits MC-induced immunosuppression and eliminates the infection of MC. This response seems to be dose-dependent with higher concentration causing speedy clearance. Faster onset of action subsequently leads to good compliance.

The age ranged from 2 years to 14 years in our study of which mean age was $8.77(\mathrm{SD} \pm 2.52)$ years in $5 \% \mathrm{KOH}$ group and $7.47(\mathrm{SD} \pm 3.02)$ years in $10 \% \mathrm{KOH}$ group which is comparable to the study of Farhana Muzaffar 11 where the mean age was $4.5(\mathrm{SD} \pm 1.99)$ years in $5 \% \mathrm{KOH}$ group while $5.3(\mathrm{SD} \pm 2.05)$ years in $10 \% \mathrm{KOH}$ group, respectively. However, in Qureshi et $a l$, study the mean age of patients was $20.53(\mathrm{SD} \pm 8.17$ ) years. ${ }^{17}$

The mean number of lesions in our Group A and $\mathrm{B}$ was 14.67 (SD \pm 7.32$)$ and $16.53(\mathrm{SD} \pm 10.97)$ respectively. Our study showed that treatment was efficacious in $05(21.7 \%)$ and $13(76.5 \%)$ patients, from groups $A$ and $B$ respectively, who had $<25$ lesions. Ucmak et $a l, 18$ studies evaluated the effectiveness and outcomes of everyday applications of Potassium Hydroxide $(\mathrm{KOH})$ solution at $2.5 \%$ and $5 \%$ concentrations, two 


\section{Molluscum Contagiosum Treatment}

times every day in 29 youngsters with Molluscum contagiosum. Patients with fewer lesions remitted better $(p<0.05)$.

In our study female was outnumbered by male with a male ratio female of 1.7:1, which is comparable with the study of Sudany et al, ${ }^{19}$ which reported a male ratio female of 1.6:1. The same study showed that the total number of lesions per patient was in the range of 1 to 75 with a mean \pm SD of $8.95 \pm 9.32$ lesions, at the end of the study $64 \%$ of patients of $10 \% \mathrm{KOH}$ group showed complete clearance of lesion and total 181 (82.3\%) lesions out of 220 showed complete clearance.

There was no severe local or systemic adverse reaction reported in our study. The only finding was slight erythema immediate post application which infers that $10 \% \mathrm{KOH}$ is an efficacious and safe modality of treatment similar results can be seen in a study performed by Teixido et al, ${ }^{20}$ and Heo et al. ${ }^{21}$

\section{LIMITATIONS OF THE STUDY}

The limitation of our study was a single-centre study, a smaller sample size, and a study based on pediatric population only. Further studies with larger sample sizes are required with the involvement of the adult population so that the results can be generalized.

\section{CONCLUSION}

$\mathrm{KOH} 10 \%$ is an efficient modality for the treatment of molluscum contagiosum in the pediatric age group as compared to $\mathrm{KOH} 5 \%$. It is safe, effective, and easily manageable at home and in a country, with meagre resources like ours it is cost-effective as well.

\section{Conflict of Interest: None.}

\section{Authors' Contribution}

HSB: Concept and design of the study, data analysis, NA: Drafting and study supervision, final approval of version, final approval of version, AUB: Data analysis, revisiting critically, OF: Data analysis, AWAQ: Data analysis.

\section{REFERENCES}

1. Leung AKC, Barankin B, Hon KLE. Molluscum contagiosum: an update. Recent Pat Inflamm Allergy Drug Discov 2017; 11(1): 2231.

2. Fasih $\mathrm{S}$, Arif $\mathrm{AB}$, Younas $\mathrm{S}$. Pattern of skin diseases in Abbas Institute of Medical Sciences, Muzaffarabad. Pak J Physiol 2017; 13(4): 26-29.

3. Müller CSL, Laue M, Kremer K, Becker S, Vogt T, Smola S. Molluscum-contagiosum-virus in einer epidermalzyste. J Dtsch Dermatol Ges 2018; 16(9): 1144-1146.

4. Arshad AR. Molluscum contagiosum. J Pioneer Med Sci 2015; 5(4): 124-128.

5. Olsen JR, Gallacher J, Piguet V, Francis NA. Epidemiology of molluscum contagiosum in children: a systematic review. Fam Pract 2014; 31(2): 130-136.
6. Meza-Romero R, Navarrete-Dechent C, Downey C. Molluscum contagiosum: an update and review of new perspectives in aetiology, diagnosis, and treatment. Clin Cosmet Investig Dermatol 2019; 12(2): 373-381.

7. Forbat E, Al-Niaimi F, Ali FR. Molluscum contagiosum: review and update on management. Pediatr Dermatol 2017; 34(5): 504515.

8. van der Wouden JC, van der Sande R, Kruithof EJ, Sollie A, van Suijlekom-Smit LW, Koning S. Interventions for cutaneous molluscum contagiosum. Cochrane Database Syst Rev 2017; 5(5): CD004767.

9. Viswanath V, Shah RJ, Gada JL. Intralesional 5-fluorouracil: a novel therapy for extensive molluscum contagiosum in an immunocompetent adult. Ind J Dermatol Venereol Leprol 2017; 83(2): 265-266.

10. Fatima S, Ejaz A, Anwar A. Comparison of the efficacy of intralesional purified protein derivative (PPD) with cryotherapy in the treatment of cutaneous warts. Pak Armed Forces Med J 2019; 69(5): 965-970.

11. Muzaffar F, Faiz F. Comparison of 5\% Potassium Hydroxide with $10 \%$ Potassium Hydroxide solution in the treatment of molluscum contagiosum: a comparative study. J Pak Assoc Dermatol 2014; 24(4): 337-341.

12. Rahman A, Akhtar A, Tabassum S, Ahmad RS. Treatment of molluscum contagiosum with $10 \%$ potassium hydroxide solution. J Rawalpindi Med Coll 2017; 21(3): 248-252.

13. Can B, Topaloglu F, Kavala M. Treatment of pediatric molluscum contagiosum with 10\% Potassium Hydroxide solution. J Dermatolog Treat 2014; 25(3): 246-248.

14. Romiti R, Ribe iro AP, Grinblat BM. Treatment of molluscum contagiosum with potassium hydroxide: a clinical approach in 35 children. Pediatr Dermatol 1999; 16(3): 228-230.

15. Short KA, Fuller C, Higgins EM. Double-blind, randomized placebo-controlled trial of the use of topical $10 \%$ Potassium Hydroxide solution in the treatment of molluscum contagiosum. Pediatr Dermatol 2006; 23(3): 279-281.

16. Giner-Soriano M, Teixidó C, Marsal J, Díez O, Pera H, Vlacho B, et al. Randomized placebo-controlled clinical trial on efficacy and safety of topical $10 \%$ Potassium Hydroxide for molluscum contagiosum treatment in children. J Dermatolog Treat 2019; 30(8): 750-756.

17. Qureshi A, Zeb M, Jalal-ud-din M, Sheikh ZI, Alam MA, Anwar SA. Comparison of the efficacy of $10 \%$ Potassium Hydroxide solution versus cryotherapy in the treatment of Molluscum contagiosum. J Ayub Med Coll Abbottabad 2016; 28(2): 382-385.

18. Uçmak D, Akkurt MZ, Kacar SD, Sula B, Arica M. Comparative study of $5 \%$ and $2.5 \%$ Potassium Hydroxide solution for molluscum contagiosum in children. Cutan Ocul Toxicol 2014; 33(1): 54-59.

19. Al-Sudany NK, Abdulkareem DR. A comparative study of topical $10 \% \mathrm{KOH}$ solution and topical $25 \%$ podophyllin solution as home-based treatments of molluscum contagiosum. J Dermatol Dermatol Surg 2016; 20(2): 107-114.

20. Teixidó C, Díez O, Marsal J, Giner-Soriano M, Pera H, Martinez $\mathrm{M}$, et al. Efficacy and safety of topical application of $15 \%$ and 10\% Potassium Hydroxide for the treatment of Molluscum contagiosum. Pediatr Dermatol 2018; 35(3): 336-342.

21. Heo J, Park T, Kim W. The efficacy and safety of topical $10 \%$ Potassium Hydroxide for molluscum contagiosum: a systematic review and meta-analysis. J Dermatolog Treat 2021; 2(1): 1-9. 